\title{
Intravenous nicardipine in hypertensive preterm infants
}

\author{
J B Gouyon, B Geneste, D S Semama, M Françoise, J F Germain
}

\begin{abstract}
Eight preterm infants were given intravenous nicardipine, a calcium channel blocker, to treat systemic hypertension (renal artery thrombosis $(n=3)$; dexamethasone for management of bronchopulmonary dysplasia $(n=2)$; unexplained $(\mathbf{n}=3))$. Nicardipine doses ranged from 0.5 to $2.0 \mu \mathrm{g} / \mathrm{kg} / \mathrm{min}$ and were given for three to 36 days (mean (SD) 15.9 (10.3) days). Systolic blood pressure had significantly decreased after 12 and 24 hours of nicardipine treatment $(-17(17) \%$ and $-21(10)$ $\%$, respectively). Diastolic blood pressure significantly decreased after 24 hours of treatment $(-22 \pm 16 \%)$. The decrease in blood pressure remained significant over the subsequent days of treatment. No hypotension or other clinical side effects were observed.
\end{abstract}

It is concluded that intravenous nicardipine could be a first line treatment for hypertension in preterm infants. (Arch Dis Child 1997;76:F126-F127)

Keywords: nicardipine; hypertension; blood pressure.

The incidence of neonatal hypertension in neonatal intensive care units is reported to be between 0.7 to $3.2 \% .{ }^{1}$ Data on the use of antihypertensive drugs in neonates, particularly preterm infants, are scarce. The most efficacious antihypertensive drugs, such as diazoxide, sodium nitroprusside, $\beta$ blockers and angiotensin-converting enzyme inhibitors, may all induce severe side effects. ${ }^{1-3}$ Moreover, the efficacy and safety of these drugs have not been systematically reported in preterm infants who may be particularly sensitive to antihypertensive agents as has been observed with angiotensinconverting enzyme inhibitors. ${ }^{23}$

Intravenous nicardipine is effective and safe in hypertensive adults. Recently, Treluyer $e t a l^{4}$ established that continuous infusion of nicardipine $(1 \mu \mathrm{g} / \mathrm{kg} / \mathrm{min})$ was effective and safe in 14 hypertensive children including seven term neonates (personal communication). To our knowledge, no other data on the use of nicardipine in hypertensive newborn infants have been published. We therefore report our experience of nicardipine administration in eight hypertensive preterm infants.

\section{Methods}

Eight preterm infants were given intravenous nicardipine. For all patients, systolic and/or diastolic blood pressures were above the mean
+2 standard deviations for gestational age and postnatal age, according to normative values of blood pressure. ${ }^{1}$ Arterial hypertension was the result of renal artery thrombosis $(n=3)$, dexamethasone administration for management of bronchopulmonary dysplasia $(n=2)$, or remained unexplained $(n=3)$.

Blood pressure and cardiac frequency were measured using an automatic oscillometric blood pressure monitoring device (Dinamap, Critikon Inc. Tampa, Florida) when the newborn infants were quiet or asleep. These variables were recorded at least four times daily over the two days before the onset of treatment and every day throughout the treatment period. Moreover, these variables were recorded in the hour preceding the onset of nicardipine infusion and at three, six, 12 and 24 hours after treatment had started.

The initial infusion rate of nicardipine was $0.5 \mu \mathrm{g} / \mathrm{kg} / \mathrm{min}(\mathrm{n}=2)$ or $1.7 \mu \mathrm{g} / \mathrm{kg} / \mathrm{min}(\mathrm{n}=6)$. The infusion rate was modified according to therapeutic response (that is, systolic and blood pressure values in normal ranges). The maximal infusion rate was $1.56(0.45) \mu \mathrm{g} / \mathrm{kg} / \mathrm{min}$ (range 0.5 to $2 \mu \mathrm{g} / \mathrm{kg} / \mathrm{min}$ ). The duration of treatment was $15.9(10.3)$ days (range 3 to 36 days). No infant received other antihypertensive agents before or during nicardipine administration.

Measurements of plasma creatinine, sodium, and potassium concentrations were performed daily; this is routine practice in our neonatal intensive care unit.

STATISTICAL ANALYSIS

Values were expressed as mean (SD). The significance of systolic and diastolic blood pressure changes over the first day of treatment was assessed by analysis of variance for repeated measures. Significance of systolic and diastolic blood pressure changes in the first week of treatment was assessed using a Friedman test. The significance level was set at $\mathrm{P}<0.05$.

\section{Results}

The mean gestational age and birthweight of the eight hypertensive preterm infants were 31.6 (2.9) weeks (range 28-36 weeks) and 1675 (605) g (range 960-2700 g), respectively. All infants were boys. Postnatal age at the onset of nicardipine treatment was 120 days in a 28 week preterm infants and 17(8) days (range 5-33 days) in the seven other infants.

At the start of treatment the mean systolic and diastolic blood pressure were 100.7 (14.7) $\mathrm{mm} \mathrm{Hg}$ and 66.0 (12.0) $\mathrm{mm} \mathrm{Hg}$, respectively. The figure indicates the course of blood 
Table 1 Per cent changes in systolic and diastolic blood pressure in hypertensive preterm infants given intravenous nicardipine

\begin{tabular}{llll}
\hline $\begin{array}{c}\text { Days of nicardipine } \\
\text { administration }\end{array}$ & No & $\begin{array}{l}\text { Changes (\%) } \\
\text { in systolic blood } \\
\text { pressure }\end{array}$ & $\begin{array}{l}\text { Changes (\%) in } \\
\text { diastolic blood } \\
\text { pressure }\end{array}$ \\
\hline 1 & 8 & $-12.7 \pm 13.6$ & $-17.3 \pm 17.7$ \\
2 & 8 & $-21.6 \pm 14.6$ & $-28.0 \pm 21.1$ \\
3 & 8 & $-21.4 \pm 7.7$ & $-29.1 \pm 14.0$ \\
4 & 8 & $-25.6 \pm 7.5$ & $-32.3 \pm 13.3$ \\
5 & 7 & $-26.0 \pm 11.1$ & $-30.5 \pm 11.3$ \\
6 & 7 & $-25.1 \pm 10.5$ & $-31.7 \pm 13.0$ \\
7 & 7 & $-22.1 \pm 10.9$ & $-24.9 \pm 14.0$ \\
\hline
\end{tabular}

pressure during the first day of treatment in these eight neonates. Compared with the initial blood pressure values (Ho), a significant decrease in systolic blood pressure was observed at 12 and 24 hours of treatment $(-17$ $(17) \%$ and $-21(10) \%$, respectively). A significant decrease in diastolic blood pressure was observed only at 24 hours of treatment $(-22(16) \%)$.

One infant was treated only for three days and the others were treated for seven to 36 days. Compared with the initial blood pressure values (average of blood pressure values in the two days preceding nicardipine administration), a decrease in systolic and diastolic blood pressure values occurred in the first week of antihypertensive treatment (table 1). The decrease in systolic and diastolic blood pressures was significant $(P<0.01)$.

Hypotension, oedema, and tachycardia were not observed during treatment of the infants. Sodium, potassium, and creatinine concentrations did not vary from the baseline values. Blood pressure remained in the normal range for all infants after treatment had been discontinued. One infant presenting with mitochondrial disease, died after 14 months. All other infants were alive at a mean age of 24 (18) months (range 6-57 months).

\section{Discussion}

Nicardipine lowers blood pressure by decreasing systemic vascular resistance. To the best of our knowledge, this is the first study of the systematic use of nicardipine in hypertensive preterm infants. Continuous intravenous nicardipine administration in these eight hypertensive preterm infants was both efficacious and safe. The decrease in blood pressure was progressive (fig 1 and table 1), which is imperative if acute changes in cerebral blood flow velocity are to be avoided, which occurred in some preterm infants presenting with an acute drop in blood pressure induced by captopril. ${ }^{3}$ We observed that continuous infusion of nicardipine allowed the doses to be adapted to lower the blood pressure to normal values. ${ }^{1}$

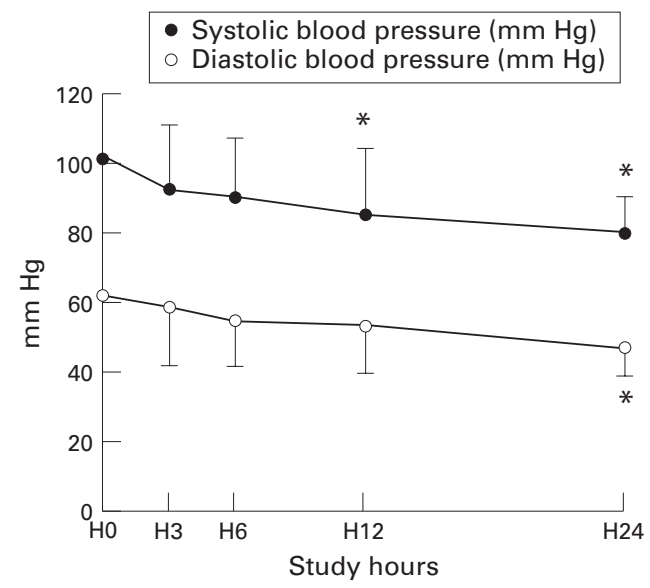

Figure 1 Systolic and diastolic blood pressure values before and at three, six, 12 and 24 hours of nicardipine administration in eight hypertensive preterm infants. ${ }^{\star} P<0.05$.

Importantly, there were no side effects in these preterm infants treated for up to 36 days. Treluyer et al also highlighted the lack of side effects of intravenous nicardipine in children. ${ }^{4}$

However, Levene et al reported a sudden drop in blood pressure drop in two of four severely asphyxiated term neonates receiving low dose nicardipine $(0.33 \mu \mathrm{g} / \mathrm{kg} / \mathrm{min})$. Nicardipine was given to obtain cerebral protection. All four infants had a normal mean arterial blood pressure before starting nicardipine and the cause for the collapse of two infants remained unclear. Nicardipine metabolism is mainly hepatic (cytochrome P450 IIIA) and we hypothesise that perinatal asphyxia might have induced hepatic dysfunction and changed nicardipine metabolism in these neonates. ${ }^{6}$

These overall data suggest that intravenous nicardipine could be a first line drug for the treatment of hypertension in preterm infants. However, to define the optimal conditions for the administration of nicardipine further pharmacokinetic and clinical studies are advisable.

1 Rasoulpour M, Marinelli KA. Systemic hypertension. Clin Perinatol 1992;19:121-37.

2 Tack ED, Perlman JM. Renal failure in sick hypertensive premature infants receiving captopril therapy. $\mathcal{F}$ Pediatr premature infants

3 Perlman JM, Volpe JJ. Neurologic complications of captopril treatment of neonatal hypertension. Pediatrics 1989;83: 47-52.

4 Treluyer JM, Hubert P, Jouvet P, Couderc S, Cloup M. Intravenous nicardipine in hypertensive children. Eur $\mathcal{F}$ Pediatr 1993;152:712-14.

5 Levene MI, Gibson NA, Fenton AC, Papathoma E, Barnett D. The use of a calcium-channel blocker, nicardipine, for severely asphyxiated newborn infants. Dev Med Child Neurol 1990;32:567-74.

6 Higuchi S, Shiabora Y. Metabolic fate of nicardipine hydrochloride, a new vasodilatator, by various species in vitro. Xenobiotica 1989;7:889-96. 